\title{
Gallic acid caused cultured mice TM4 Sertoli cells apoptosis and necrosis
}

\author{
Wanhong $\mathrm{Li}^{1,2,3}$, Xiangpeng $\mathrm{Yue}^{1,2,3}$, and Fadi $\mathrm{Li}^{1,2,3,4, *}$
}

\footnotetext{
* Corresponding Author: Fadi Li

Tel: +86-0931-891-5213, Fax: +86-0931-891-5213,

E-mail: lifd@|zu.edu.cn

'State Key Laboratory of Grassland Agro-ecosystems, College of Pastoral Agriculture Science and

Technology, Lanzhou University, Lanzhou 730020,

China

2 Key Laboratory of Grassland Livestock Industry Innovation, Ministry of Agriculture and Rural Affairs, Lanzhou University, Lanzhou 730020, China

${ }^{3}$ Engineering Research Center of Grassland Industry,

Ministry of Education; Lanzhou University, Lanzhou, 730020, China

${ }^{4}$ Biotechnology Engineering Laboratory of Gansu

Meat Sheep Breeding, Minqin, 733300, China

ORCID

Wanhong Li

https://orcid.org/0000-0002-2155-6863

Xiangpeng Yue

https://orcid.org/0000-0002-0633-359X

Fadi Li

https://orcid.org/0000-0002-0143-4199
}

Submitted Apr 20, 2018; Revised Jul 29, 2018; Accepted Sept 28, 2018
Objective: The study was designed to determine the cytotoxic effect of gallic acid (GA), obtained by the hydrolysis of tannins, on mice TM4 Sertoli cells apoptosis.

Methods: In the present study, non-tumorigenic mice TM4 Sertoli cells were treated with different concentrations of GA for $24 \mathrm{~h}$. After treatment, cell viability was evaluated using WST-1, mitochondrial dysfunction, cells apoptosis and necrosis was detected using JC-1, Hoechst 33342 and propidium iodide staining. The expression levels of Cyclin B1, proliferating cell nuclear antigen (PCNA), Bcl-2-associated X protein (BAX), and Caspase-3 were also detected by quantitative real-time polymerase chain reaction and Western-blotting.

Results: The results showed that 20 to $400 \mu \mathrm{M}$ GA inhibited viability of TM4 Sertoli cells in a dose-dependent manner. Treatment with $400 \mu \mathrm{M}$ GA significantly inhibited PCNA and Cyclin B1 expression, however up-regulated BAX and Caspase-3 expression, caused mitochondrial membrane depolarization, activated Caspase-3, and induced DNA damage, thus, markedly increased the numbers of dead cells.

Conclusion: Our findings showed that GA could disrupt mitochondrial function and caused TM4 cells to undergo apoptosis and necrosis.

Keywords: Apoptosis; Gallic Acid; TM4 Sertoli Cell

\section{INTRODUCTION}

Besides providing energy and protein in animals' nutrition, forages or other subsidiary agricultural products contain other nutrients and a wide variety of secondary metabolites. One group of secondary metabolites, tannins, are widely contained in sorghum ( 0.5 to $1.3 \mathrm{~g} / 100 \mathrm{~g}$, dry matter [DM]), grape (2 to $8 \mathrm{~g} / 100 \mathrm{~g}$ in skin, and 13 to $15 \mathrm{~g} / 100 \mathrm{~g}$ in seed, $\mathrm{DM})$, and leguminous forages (0.4 to $11.6 \mathrm{~g} / 100 \mathrm{~g}, \mathrm{DM})$ [1-3], and have long been the object of interest [4]. In livestock husbandry, tannins have been studied for their detrimental effects on herbivory, pathogens, parasites, or toxicity. Tannins also affect feed utilization and especially protect protein from fermentation including a shift in $\mathrm{N}$ excretion from urine to feces, and reduce ruminal methanogenesis $[5,6]$.

Gallic acid (3,4,5-trihydroxybenzoic acid, GA), obtained by the hydrolysis of tannins, is a plant polyhydroxy phenol with well-known natural anti-oxidant ability [7]. As a strong natural anti-oxidant to scavenge reactive oxygen species (ROS), GA has been used as antioxidant food additive to inhibit oxidation of processed food products [8]. GA is easily absorbed in blood plasma after intake of tannins rich food [9]. Controversially, GA also is proposed to be pro-oxidant with its ability to inhibit superoxide dismutase and enhances ROS $[8,9]$, and affects animal reproduction. To our knowledge, GA significantly decreases basal activities of $3 \beta$-hydroxysteroid dehydrogenases (HSD) and 17 $\beta$-HSD in the testes and effects testosterone concentration leading to low sperm counts and quality in mice [10]. In mammals, 
Sertoli cells play a central role in sexual differentiation and in spermatogenesis. Taken together, we hypothesized that in males, GA may induce Sertoli cells apoptosis to affect spermatogenesis. Thus, the aim of this study was to investigate the effects of GA on apoptosis and necrosis of non-tumorigenic mice TM4 Sertoli cells via detecting the mitochondrial dysfunction, Cyclin $\mathrm{B} 1$, proliferating cell nuclear antigen $(P C N A), \mathrm{Bcl}-2$-associated $\mathrm{X}$ protein $(B A X)$, and Caspase-3 gene expression.

\section{MATERIALS AND METHODS}

\section{Reagents}

The Dulbecco's modified Eagle's medium (DMEM), fetal bovine serum (FBS), horse serum, trypsin-ethylenediaminetetraacetic acid solution and phosphate buffer saline (PBS) were purchased from Life Technologies (Carlsbad, CA, USA). BCA assay kit, goat anti-rabbit IgG antibody, rabbit anti-PCNA, rabbit antiBAX, rabbit anti-Caspase-3, and rabbit anti-GAPDH were purchased from Bioss Biotechnology (Beijing, China). WST1 kit was purchased from Roche (Mannheim, Germany). IP cell lysis buffer, JC-1 kit, beyoECL plus kit, apoptosis and necrosis assay kit were purchased from Beyotime Biotechnology (Nantong, China). Trizol reagent, primescript RT reagent kit with gDNA eraser and SYBR premix Ex Taq kit were purchased from Takara (Dalian, China). GA was purchased from Sigma (St. Louis, MO, USA). All other reagents were purchased from Sangon Biotech (Shanghai, China).

\section{Cell culture}

The non-tumorigenic mice TM4 Sertoli cell line [11] was purchased from BioHermes (Wuxi, China) and was seeded as monolayer cultured in DMEM supplemented with 5\% FBS and $2.5 \%$ horse serum at $37^{\circ} \mathrm{C}$ and $5 \% \mathrm{CO}_{2}$ in humidified air. After completely attached, the cells were treated with pre-warmed fresh DMEM with or without GA for different experiments.

\section{Cell viability assays}

To determine the effects of GA on TM4 cells viability and growth, TM4 cells $\left(1 \times 10^{4}\right)$ were seeded in a 96-well plate per well and treated with GA $(0,20,50,100,200$, and $400 \mu \mathrm{M})$ according to previous studies $[10,12]$ for $12 \mathrm{~h}$ and $24 \mathrm{~h}$. At the end of the culture period, $10 \mu \mathrm{L}$ WST-1 solution was added to each well, and incubated for $1.5 \mathrm{~h}$. The absorbance was measured at $460 \mathrm{~nm}$ using ELX 808 microplate reader (BioTek, Winooski, VT, USA). The absorbance of culture medium plus WST-1 without cell was invoked as background control. TM4 cells viability were given in the relative percentage of the control group treated without gallic acid.

\section{Mitochondrial membrane potential assays}

The mitochondrial membrane potential (MMP) detection was performed according to the manufacturer's MMP JC-1 de- tection kit instructions. Non-damaged (healthy) mitochondria of high MMP were indicated by red fluorescence due to JC-1 staining and were accumulated in matrix of mitochondria to form a polymer as JC-1 aggregate. While in damaged cells, the MMP was breaking down and the JC-1 monomers were seen dispersed through the entire cell and indicated by the green fluorescence [13]. After 0, 20, and $400 \mu \mathrm{M}$ GA treated for 24 $\mathrm{h}, \mathrm{TM} 4$ cells were washed twice with PBS. One $\mathrm{mL}$ fresh culture medium/JC-1 working solution (1:1) was hereby added per well, and incubated for $20 \mathrm{~min}$ at $37^{\circ} \mathrm{C}$. Then, TM4 cells were washed twice with JC-1 washing buffer. Subsequently, MMP was reviewed on a fluorescence microscope (Olympus, Tokyo, Japan) under blue and green light at the same exposure parameters, respectively. The red and green fluorescence images were merged using cellSens Standard software (Olympus, Japan).

\section{Hoechst 33342 and propidium iodide staining}

After GA $(0,20$, and $400 \mu \mathrm{M})$ treatment for $24 \mathrm{~h}$ in 24 -well plates, cells were washed twice with cold PBS, then, incubated with $5 \mu \mathrm{L}$ Hoechst 33342 and $5 \mu \mathrm{L}$ propidium iodide (PI) in $1 \mathrm{~mL}$ staining solution for $20 \mathrm{~min}$ at $4^{\circ} \mathrm{C}$. After that, cells were washed with PBS and nuclear morphological changes were observed using fluorescence microscope (Olympus, Japan) under ultraviolet light and green light at same exposure parameters, respectively. The dark blue cells with normal nuclei were counted as viable cells, while the bright blue and red cells as necrosis [14]. Total cells and necrotic cells were counted, and the percentages of survival cells were calculated.

RNA isolation and real-time polymerase chain reaction TM4 cells were collected after GA $(0,20$, and $400 \mu \mathrm{M})$ treated for $24 \mathrm{~h}$, and total RNA was isolated using Trizol reagent according to the literature. RNA quantity and quality were estimated by NanpDrop 2000 spectrophotometer (Thermo Scientific, Waltham, MA, USA). The first-strand cDNA was synthesized using primescript RT reagent kit with gDNA eraser from 2 $\mu \mathrm{g}$ total RNA after removing genome DNA. Proliferation and apoptosis related genes expression were detected with specific primers on the Agilent Mx3000P real-time system (Agilent, Santa Clara, CA, USA) using SYBR premix Ex Taq kit as follows: preheating at $94^{\circ} \mathrm{C}$ for $5 \mathrm{~min} ; 35$ cycles at $94^{\circ} \mathrm{C}$ for $5 \mathrm{~s}$; and $60^{\circ} \mathrm{C}$ for $30 \mathrm{~s}$. Fluorescence signals were collected at the endpoint of each extension step. At the end of each amplification, amplified products were subjected to a dissociation gradient to verify the amplification of single product denaturation at the anticipated temperature. Amplification was carried out as recommended by the manufacturer for a $20 \mu \mathrm{L}$ reaction size contained $1 \mu \mathrm{L}$ of cDNA, 5 pmol of each primer, $10 \mu \mathrm{L}$ of SYBR enzyme mix. Primers (Table 1) were designed to span introns to avoid false results from genomic DNA amplification. Each cDNA product was tested in triplicate. The levels of Cyclin 
Table 1. List of primers used for quantitative real-time polymerase chain reaction

\begin{tabular}{|c|c|c|c|}
\hline Gene (ID) & Primer sequence $5^{\prime}-3^{\prime}$ & Fragment length (bp) & Annealing temperature $\left({ }^{\circ} \mathrm{C}\right)$ \\
\hline GAPDH & F:AGGTCGGTGTGAACGGATTTG & & \\
\hline XM_017321385.1 & R: TGTAGACCATGTAGTTGAGGTCA & 123 & 60 \\
\hline Caspase-3 & F:AGCAGCTTTGTGTGTGTGATTCTAA & & \\
\hline XM_017312543.1 & R:AGTTTCGGCTTTCCAGTCAGAC & 137 & 60 \\
\hline$B A \bar{X}$ & F: CAGGATGCGTCCACCAAGAA & & \\
\hline XM_011250780.2 & R: GCAAAGTAGAAGAGGGCAACCA & 197 & 60 \\
\hline PCNA & F: TAAAGAAGAGGAGGCGGTAA & & \\
\hline NM_011045.2 & R: TAAGTGTCCCATGTCAGCAA & 175 & 60 \\
\hline Cyclin B1 & F: AGATGCAGTTGGCACCATGT & & \\
\hline NM_172301.3 & R:TTCGACAACTTCCGTTAGCCT & 148 & 60 \\
\hline
\end{tabular}

GAPDH, glyceraldehyde-3-phosphate dehydrogenase; $B A X, B C l$-2-associated X protein; $P C N A$, proliferating cell nuclear antigen.

B1, PCNA, BAX, and Caspae-3 were normalized against glyceraldehyde-3-phosphate dehydrogenase (GAPDH) levels as relative fold change $\left(2^{-\Delta \Delta C t}\right)$.

\section{Western blotting analysis}

Total protein was isolated from TM4 cells after treatment with GA $(0,20,400 \mu \mathrm{M})$ for $24 \mathrm{~h}$ using IP cell lysis buffer. After centrifuged at $10,000 \times \mathrm{g}$ at $4^{\circ} \mathrm{C}$ for $15 \mathrm{~min}$, total protein concentrations were estimated by BCA assay. Approximately 20 $\mu \mathrm{g}$ proteins were separated by sodium dodecyl sulfate-polyacrylamide gel electrophoresis on a polyacrylamide gel and then transferred onto polyvinylidene fluoride membranes with a pore size of $0.45 \mu \mathrm{m}$. After blocking with $5 \%$ non-fat milk for $2 \mathrm{~h}$ at room temperature, membranes were incubated with primary antibodies (1:1,000 for GAPDH and 1:800 for others) overnight at $4^{\circ} \mathrm{C}$. After that, membranes were washed 3 times with PBS containing $0.1 \%$ Tween 20, then, incubated for 1 $\mathrm{h}$ with HRP-conjugate goat anti-rabbit secondary antibody $(1: 5,000)$ at room temperature. After washed 3 times, the western blot images were captured by Tanon 5200 Chemiluminescent image systems (Tanon, Shanghai, China) using beyoECL plus kit.

\section{Statistical analysis}

All experiments were repeated independently at least three times, and data were presented as mean \pm standard error of the mean. Statistical analysis was carried out with SPSS 13.0 program (SPSS, Chicago, IL, USA). Normality of distribution were analyzed by one-sample Kolmogorov-Smirnov test. The homogeneity of variance was analyzed by Lenven's test. The significance was analyzed by one-way analysis of variance test and multiple comparisons between groups were compared with LSD analysis of variance. Less than $0.05 \mathrm{p}$ value was considered statistically significant.

\section{RESULTS}

Effects of gallic acid on cell viability
Cell viability was significantly reduced by treatments with 200 and $400 \mu \mathrm{M}$ GA for $12 \mathrm{~h}$ (Figure 1A). For $24 \mathrm{~h}$ treatments, GA significantly reduced cell viability compared with the control group $(\mathrm{p}<0.05)$ (Figure 1B) in a concentration dependent manner. The number of detached cells was increased in the GA treatment groups. Thus, the cellular density was decreased (Figure 1C). Based on these data, treatments with 20 and 400 $\mu \mathrm{M}$ for $24 \mathrm{~h}$ were selected for the subsequent experiments in this study.

\section{Mitochondrial dysfunction}

MMP depolarization is generally perceived as an early sign of apoptosis. When MMP depolarization occurs, JC-1 staining shifts from JC-1 aggregates to JC-1 monomers (green fluorescence) [13]. As shown in Figure 2, compared to control group significant MMP depolarization was detected after 20 and 400 $\mu \mathrm{M}$ GA treatment, as demonstrated by the strong green fluorescence (Figure 2D, 2G) and pale red fluorescence (Figure 2E, $2 \mathrm{H})$. Thus, these results clearly show that GA decreased TM4 cells' MMP compared to control group with red-orange fluorescence (Figure 2C) to yellow-green (Figure 2F, $20 \mu \mathrm{M}$ ) and green (Figure 2I, $400 \mu \mathrm{M}$ ) in a concentration dependent manner.

\section{Cell necrosis and apoptosis assay}

As shown in Figure 3, most of the normal control group cells were stained with few Hoechst 33342 and PI. After treatment with 20 and $400 \mu \mathrm{M}$ GA, the number of nuclei stained with bright blue and red fluorescence showing late apoptosis or necrosis was significantly increased (Figure 3F, 3I). Apoptosis cells with condensed and fragmented nuclei after GA treatment were observed with Hoechst 33342 (Figure 3D, 3G; arrow). Based on the nuclear morphological changes after two dyes staining, the cells survival rates were significantly decreased from $93.1 \%$ (control) to $48.6 \%(20 \mu \mathrm{M}, \mathrm{p}<0.05)$, and $23.9 \%(400 \mu \mathrm{M}, \mathrm{p}<0.05)$ after GA treatment, respectively (Figure 3J). 

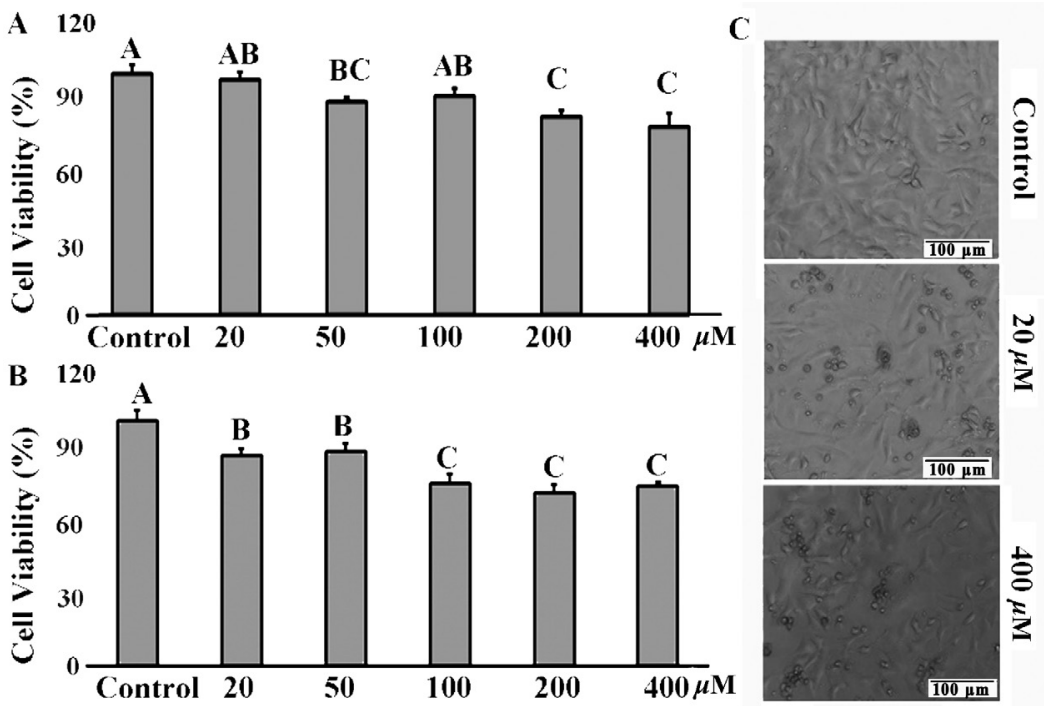

Figure 1. Cytotoxic effects of GA on mice TM4 cells. (A) and (B) Cell viability was determined by WST-1 assay after 20, 50, 100, 200, and 400 $\mu \mathrm{M} \mathrm{GA} \mathrm{treated} \mathrm{for} 12 \mathrm{~h}$ and 24 h. (C) TM4 cell morphological changes were captured with Olympus microscope (100x) after 20 and $400 \mu$ M GA treated for 24 h. Photomicrographs were representatives of three independent experiments. GA, gallic acid. Data were expressed as mean (\% of control group) \pm standard error of the mean of five independent experiments. Significant difference was defined as $p<0.05$, and the data with different capital letters in the same column show a significant difference.

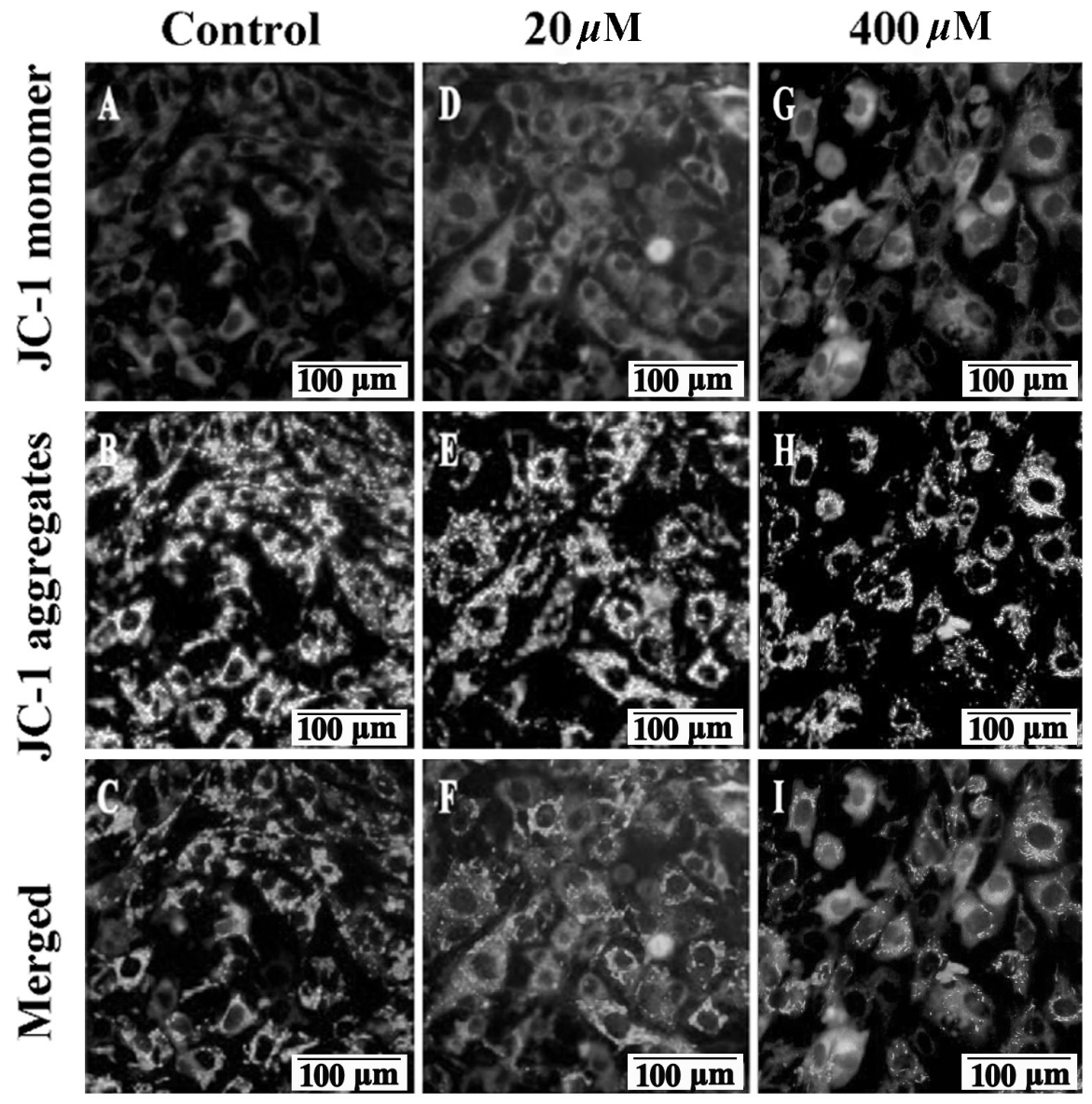

Figure 2. Effects of GA on mice TM4 cells mitochondrial membrane potential. Representative images of JC-1 stained TM4 cells were captured with Olympus microscope (100x) after $24 \mathrm{~h}$ treatment. High MMP in TM4 cells in control group emits strong red fluorescence (A) and pale green fluorescence (B). While, low MMP in $20 \mu M$ GA treated group ( $D$ and $E$ ) and in $400 \mu \mathrm{M}(\mathrm{G}$ and $\mathrm{H}) \mathrm{GA}$ treated group was indicated by pale red fluorescence and strong green fluorescence, respectively. In the merged picture (C) of (A and B), (F) of (D and E) and (I) of (G and H), the cells shift from red-orange fluorescence to green fluorescence with a concentration dependent manner. $G A$, gallic acid; MMP, mitochondrial membrane potential. Bars indicate $100 \mu \mathrm{m}$. 

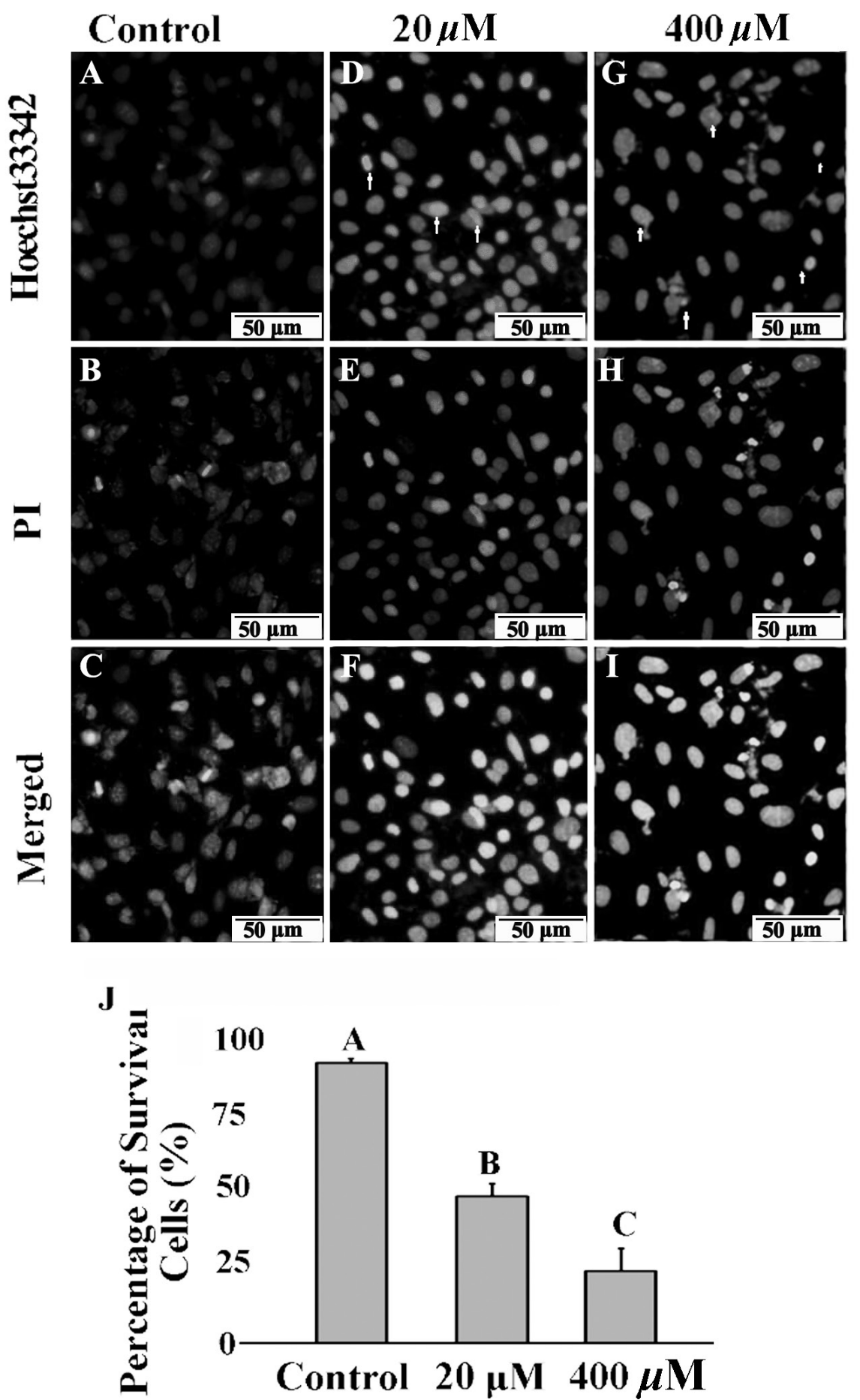

Figure 3. Effects of GA on mice TM4 cells necrosis and apoptosis. After PI/Hoechst 33342 staining, TM4 cells displayed pale blue and red fluorescence with Hoechst 33342 (A) and propidium iodide (PI) (B) stained in the control group. TM4 cells displayed strong blue and red fluorescence after $20 \mu \mathrm{M}(\mathrm{D}, \mathrm{E})$ and $400 \mu \mathrm{M}(\mathrm{G}, \mathrm{H}) \mathrm{GA}$ treated for $24 \mathrm{~h}$. In the merged picture (C) of (A and B), (F) of (D and E) and (I) of (G and H), the cells appeared pink with a concentration dependent manner. Arrows indicate typical morphological feature of condensed and fragmented nuclei in apoptosis cells. Bars indicate $50 \mu \mathrm{m}$. Ratio of survival cells in different treatment were elevated (J). GA, gallic acid. Data were expressed as mean \pm standard error of the mean of three independent experiments. Significant difference was defined as $p<0.05$, and the data with different capital letters in the same column show a significant difference.

Effects of gallic acid on apoptosis-related genes expression

After $24 \mathrm{~h}$ treatments, $400 \mu \mathrm{M}$ GA markedly inhibited Cyclin
B1, PCNA mRNA expression and PCNA protein expression $(\mathrm{p}<0.05)$. However, as for apoptosis-related genes, $B A X$ and Caspase-3 mRNA were significantly up-regulated $(\mathrm{p}<0.05)$. 
Consistent with these results, Procaspase- 3 and Cleaved caspase- 3 protein also significantly up-regulated $(\mathrm{p}<0.05)$ after $400 \mu \mathrm{M}$ GA treatment (Figure 4).

\section{DISCUSSION}

Previous studies indicated that GA is easily absorbed in blood plasma and the concentrations of total metabolites reached 4 $\mu \mathrm{M}$ after ingestion of $50 \mathrm{mg}$ GA rom Assam black tea [15]. In vitro studies, the $50 \%$ inhibitory concentration of GA for primary human pulmonary fibroblast cells is $300 \mu \mathrm{M}$ [16]. Here, we evaluated the cytotoxic effects of 20 to $400 \mu \mathrm{M}$ GA on mice TM4 cells. The results showed that the growth of TM4 cells was inhibited by GA in a concentration dependent manner, and the percentage of surviving cells declined after treatment with GA for $24 \mathrm{~h}$. To our knowledge, other phenolic compounds such as Gossypol, Quercitrin occurring in fruits and vegetables have been found to induce pathological changes in testicular cells [17-19]. Interestingly, some phenolic com- pounds, such as Romarinic acid may have protective effects on the male reproductive system [20].

PCNA has been used as a biomarker in regulation of apoptosis. Cyclin B1 ensures the cells go through G2/M checkpoint via binding with cyclin-dependent kinase [21]. For example, down-regulation of PCNA and Cyclin B1 gene expression in mouse spermatogonial GC-1 cells resulted in significantly increased apoptosis index and caused G2/M cell cycle arrest $[22,23]$. It has been shown that GA arrested cancer cells at the G2/M transition during cells cycle phase and induced apoptosis [24-26]. So, we did not determine the cell cycle in this study, based on $400 \mu \mathrm{M}$ GA inhibited PCNA and Cyclin B1 expression.

In addition, the cytotoxic effect of GA on mice TM4 cells may associate with ROS accumulation. Our results showed that $400 \mu \mathrm{M}$ GA significantly induced BAX expression. BAX is a pro-apoptotic member of the BCL2 family [23], its oligomerization and channel formation caused mitochondrial membrane permeabilization via inducing cytochrome $\mathrm{c}$ release
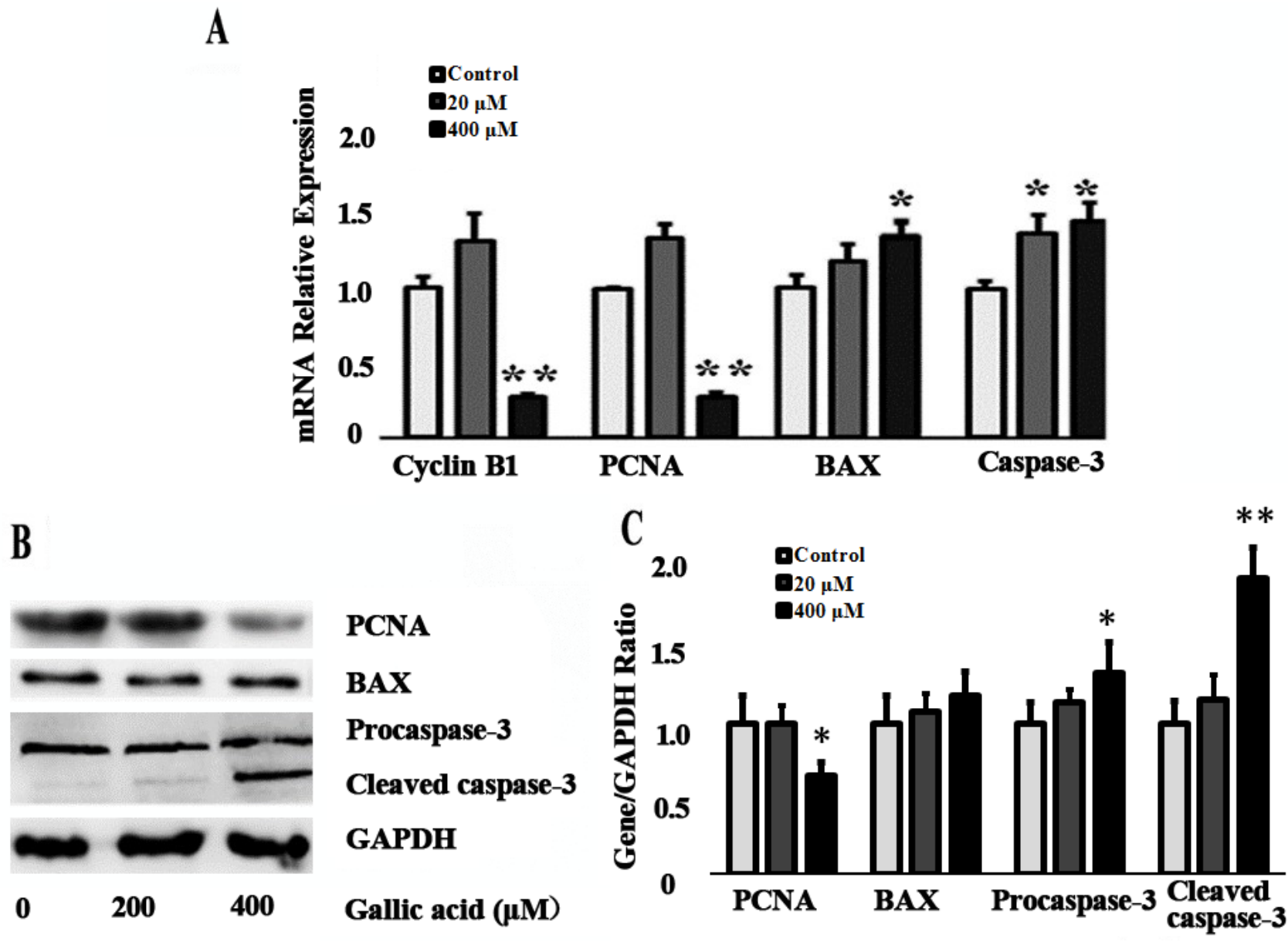

Figure 4. Effect of GA on the apoptosis related genes expression level. (A) The expression of Cyclin B1, PCNA, BAX, and Caspase-3 mRNA was determined by quantitative real-time polymerase chain reaction in mice TM4 cells after 20 and $400 \mu \mathrm{M}$ GA treatment for $24 \mathrm{~h}$. (B) The expression of PCNA, BAX, Proaspase-3 and Cleaved caspase-3 protein was determined by western blotting. GA, gallic acid; PCNA, proliferating cell nuclear antigen; BAX, BCl-2-associated X protein; Data were expressed as mean \pm standard error of the mean of three independent experiments. Significant difference was identified as ${ }^{*} p<0.05,{ }^{* *} p<0.01$, compared with control group. 
$[27,28]$. Cytochrome $\mathrm{c}$ release results in mitochondrial uncoupling and ROS accumulation [29]. Previously studies demonstrated that gallic acid significantly increased intracellular $\mathrm{H}_{2} \mathrm{O}_{2}$ production, caused accumulation of ROS and resulted mitochondrial dysfunction, thus induced mice spermatogonia (GC-1), spermatocytes (GC-2), and TM3 Leydig cells apoptosis $[12,30]$. In this study, after GA treated, TM4 cells mitochondrial dysfunction was indicated by JC-1- monomers green fluorescence, which could promote cell apoptosis.

Caspase- 3 expression were significantly changed and activated cleaved Caspase- 3 was also detected. Cell shape and nuclear morphology were extremely altered during apoptosis. DNA damage was indicated using nuclei stained with bright blue and red fluorescence after incubation with Hoechast33342/ IP staining [14], and the apoptosis and necrosis ratio increased as the dose of GA increased. Fragmented nuclei were also noted in TM4 cells in this study. These results indicated that GA triggered the caspase cascade and active caspase- 3 caused DNA damage.

In Conclusion, the present work showed clearly that GA induced mice TM4 cells apoptosis and necrosis. Furthermore, GA treatment inhibited PCNA and Cyclin B1 expression and inhibited TM4 cells growth. Moreover, GA induced mitochondrial membrane permeabilization, triggered the caspase cascade, and cleaved Caspase- 3 activation, then, caused DNA damage and TM4 cells apoptosis or necrosis.

\section{CONFLICT OF INTEREST}

We certify that there is no conflict of interest with any financial organization regarding the material discussed in the manuscript.

\section{ACKNOWLEDGMENTS}

This study was funded by the National Natural Science Foundation of China (31702112), National Key Technology Support Program (2015BAD03B0504) and Gansu Province Youth Science and Technology Fund (1606RJYA245).

\section{REFERENCES}

1. Fan L, Huo QG, Zhou ZM, Zhu ZG, Cai FY. Studies on the determination of Tannin content in sorghum. J Chinese Cereals Oil Assoc 2001;16:13-7.

2. Yang JC, Du GF, Peng JZ. Comparison of cold resistance and nutritional quality of six tropical and subtropical leguminous forages during overwintering period. Partacultural Sci 2017; 34:794-801.

3. Wang Z, Ding Y, Han XM, Guo YY. Detecting on polyphenol and tannin contents in different wine grapes form Penglai region. Sino Overseas Grapevine Wine 2015:35-7.
4. Halvorson JJ, Kronberg SL, Hagerman AE. Effects of dietary tannins on total and extractable nutrients from manure. J Anim Sci 2017;95:3654-65.

5. Vissers AM, Pellikaan WF, Bouwhuis A, et al. Laminaria digitata phlorotannins decrease protein degradation and methanogenesis during in vitro ruminal fermentation. J Sci Food Agric 2018;98:3644-50.

6. Kronberg SL, Liebig MA. Condensed tannin in drinking water reduces greenhouse gas precursor urea in sheep and cattle urine. Rangeland Ecol Manag 2011;64:543-7.

7. Ye YL, Yan JN, Cui JL, et al. Dynamic changes in amino acids, catechins, caffeine and gallic acid in green tea during withering. J Food Compost Anal 2018;66:98-108.

8. Jiang J, Xiong YL. Natural antioxidants as food and feed additives to promote health benefits and quality of meat products: a review. Meat Sci 2016;120:107-17.

9. You BR, Park WH. Gallic acid-induced lung cancer cell death is related to glutathione depletion as well as reactive oxygen species increase. Toxicol In Vitro 2010;24:1356-62.

10. Abarikwu SO, Akiri OF, Durojaiye MA, Alabi AF. Combined administration of curcumin and gallic acid inhibits gallic acidinduced suppression of steroidogenesis, sperm output, antioxidant defenses and inflammatory responsive genes. J Steroid Biochem Mol Biol 2014;143:49-60.

11. Mather JP. Establishment and characterization of two distinct mouse testicular epithelial cell lines. Biol Reprod 1980;23:24352.

12. Park WH, Chang MS, Yang WM, et al. Cytoprotective effect of Panax ginseng on gallic acid-induced toxicity in TM3 mouse Leydig cells. Fitoterapia 2007;78:577-9.

13.Xie YY, Li ZZ, Lin GJ, et al. DNA interaction, cytotoxicity, apoptotic activity, cell cycle arrest, reactive oxygen species and mitochondrial membrane potential assay induced by ruthenium(II) polypyridyl complexes. Inorganica Chim Acta 2013;405:22834.

14. Begum P, Fugetsu B. Induction of cell death by graphene in Arabidopsis thaliana (Columbia ecotype) T87 cell suspensions. J Hazard Mater 2013;260:1032-41.

15. Kroon PA. Bioavailability and bioefficacy of polyphenols in humans. I. Review of 97 bioavailablity studies. Am J Clin Nutra 2006;81(Suppl 1):230S-42S.

16. You BR, Kim SZ, Kim SH, Park WH. Gallic acid-induced lung cancer cell death is accompanied by ROS increase and glutathione depletion. Mol Cell Biochem 2011;357:295-303.

17. Coutinho EM. Gossypol: a contraceptive for men. Contraception 2002;65:259-63.

18. Lamas CA, Gollucke AP, Dolder H. Grape juice concentrate (G8000((R)) ) intake mitigates testicular morphological and ultrastructural damage following cadmium intoxication. Int J Exp Pathol 2015;96:301-10.

19.Shehab NG, Abu-Gharbieh E. Phenolic Profiling and evaluation of contraceptive effect of the ethanolic extract of salsola imbri- 
cata forssk. in male albino rats. Evid-Based Complement Alternat Med 2014;2014:Article ID 695291.

20. Hajhosseini L, Khaki A, Merat E, Ainehchi N. Effect of rosmarinic acid on Sertoli cells apoptosis and serum antioxidant levels in rats after exposure to electromagnetic fields. Afr J Tradit Complement Altern Med 2013;10:477-80.

21. Huang JF, Shui KJ, Li HY, Hu MY, Zhong GH. Antiproliferative effect of azadirachtin A on Spodoptera litura Sl-1 cell line through cell cycle arrest and apoptosis induced by up-regulation of p53. Pestic Biochem Physiol 2011;99:16-24.

22. Chimento A, Sirianni R, Casaburi I, et al. 17 $\beta$-Estradiol activates GPER- and ESR1-dependent pathways inducing apoptosis in GC-2 cells, a mouse spermatocyte-derived cell line. Mol Cell Endocrinol 2012;355:49-59.

23.Zhang G, Zeng X, Zhang R, et al. Dioscin suppresses hepatocellular carcinoma tumor growth by inducing apoptosis and regulation of TP53, BAX, BCL2 and cleaved CASP3. Phytomedicine 2016;23:1329-36.

24. Hsu JD, Kao SH, Ou TT, et al. Gallic acid induces G2/M phase arrest of breast cancer cell MCF-7 through stabilization of p27 (Kip1) attributed to disruption of p27(Kip1)/Skp2 complex.
J Agric Food Chem 2011;59:1996-2003.

25.Ji BC, Hsu WH, Yang JS, et al. Gallic acid induces apoptosis via caspase- 3 and mitochondrion-dependent pathways in vitro and suppresses lung xenograft tumor growth in vivo. J Agric Food Chem 2009;57:7596-604.

26. Tan S, Guan X, Grun C, et al. Gallic acid induces mitotic catastrophe and inhibits centrosomal clustering in HeLa cells. Toxicol In Vitro 2015;30:506-13.

27. Czabotar PE, Lessene G, Strasser A, Adams JM. Control of apoptosis by the BCL-2 protein family: implications for physiology and therapy. Nat Rev Mol Cell Biol 2014;15:49-63.

28. Owens TW, Foster FM, Valentijn A, Gilmore AP, Streuli CH. Role for X-linked Inhibitor of apoptosis protein upstream of mitochondrial permeabilization. J Biol Chem 2010;285:10818.

29. Cepero E, King AM, Coffey LM, Perez RG, Boise LH. Caspase-9 and effector caspases have sequential and distinct effects on mitochondria. Oncogene 2005;24:6354-66.

30. Park W, Chang MS, Kim H, et al. Cytotoxic effect of gallic acid on testicular cell lines with increasing $\mathrm{H}_{2} \mathrm{O}_{2}$ level in GC-1 spg cells. Toxicol In Vitro 2008;22:159-63. 